\title{
Note on Nominal Rigidities and News-Driven Business Cycles
}

\author{
Kengo Nutahara ${ }^{1,2}$ \\ ${ }^{1}$ Department of Economics, Senshu University, Tokyo, Japan \\ ${ }^{2}$ The Canon Institute for Global Studies, Tokyo, Japan \\ Email: nutti@isc.senshu-u.ac.jp
}

Received July 26, 2012; revised August 27, 2012; accepted September 28, 2012

\begin{abstract}
A news-driven business cycle is a positive comovement of consumption, output, labor, and investment from the news about the future. We show that nominal rigidities, especially sticky prices, can cause it in a medium-scale DSGE economy through countercyclical movements of the price-markup. We also find that sticky wages cannot generate it, but they amplify the effects of news shocks.
\end{abstract}

Keywords: Nominal Rigidities; News-Driven Business Cycles

\section{Introduction}

A news-driven business cycle (hereafter, NDBC) is a positive comovement of consumption, labor, investment, and output from a news shock about future productivity.

It is well known that the standard real business cycle model cannot generate it. Since the paper by Beaudry and Portier [1], many models of NDBCs are proposed ${ }^{1}$.

In this paper, we focus on nominal rigidities as sources of NDBCs. We employ the model of Fujiwara, Hirose, and Shintani [7], which is an estimated medium-scale DSGE economy a la Smets and Wouters [8] with news shocks. It is shown that NDBCs are generated because of nominal rigidities, especially sticky prices. The news shock causes a boom through the countercyclical movements of price markup. We also find that sticky wages are not sources of NDBCs in our model, but sticky wages are important as frictions that amplify the effect of the news shock.

This paper is also closely related to the one by Kobayashi and Nutahara [6]. They show that sticky prices and wages can be sources of NDBCs using a simple model theoretically. However, it is not clear that nominal rigidities work in realistic models with estimated parameter values. Medium-scale DSGE models are widely used for policy analysis and we use estimated parameter values. Therefore, we show that sticky prices are important sources of NDBCs in a widely used model with estimated parameter values, but sticky wages are not.

The rest of this paper is organized as follows. Section

${ }^{1}$ For example, see papers by Jaimovich and Rebelo [2,3], Christiano, Ilut, Motto, and Rostagno [4], Kobayashi, Nakajima, and Inaba [5], and Kobayashi and Nutahara [6].
2 introduces our model. In Section 3, it is shown that nominal rigidities, especially sticky prices, are sources of NDBCs. Section 4 draws our conclusions.

\section{Model}

\subsection{Baseline Model}

Our model is the same employed by Fujiwara, Hirose, and Shintani [7], which is based on a medium-scale DSGE model of Smets and Wouters [8] with news shocks.

In our model, the representative household faces to the external habit persistence in the consumption and the adjustments costs of investments. The utilization rate of capital is variable. Nominal prices and wages are sticky and they are partially indexed to past inflation. Monetary authority follows a Taylor type nominal interest rate rule. Finally, there are many exogenous shocks that affect the economy.

The resource constraint is

$$
y_{t}=c_{y} c_{t}+i_{y} i_{t}+u_{y} u_{t}+\varepsilon_{t}^{g},
$$

where $y_{t}, c_{t}, i_{t}, u_{t}$ and $\varepsilon_{t}^{g}$ denote the output, the consumption, the investment, the capital utilization rate, and the government expenditure shock, respectively. $c_{y}, i_{y}$ and $u_{y}$ denote the steady state share in output of consumption, investment and capital utilization cost, respectively.

The consumption Euler equation is

$$
y_{t}=c_{1} c_{t}+\left(1-c_{1}\right) E_{t} c_{t+1}+c_{2}\left(\ell_{t}-E_{t} \ell_{t+1}\right)+c_{3}\left(r_{t}-E_{t} \pi_{t+1}\right) \text {, }
$$

where 


$$
\begin{aligned}
& c_{1}=(\lambda / \gamma) /(1+\lambda / \gamma), \\
& c_{2}=\left(\sigma^{c}-1\right)\left(w^{h} \ell / c\right) /\left[\sigma^{c}(1+\lambda / \gamma)\right], \\
& c_{2}=(1-\lambda / \gamma) /\left[\sigma^{c}(1+\lambda / \gamma)\right],
\end{aligned}
$$

$\lambda$ denotes the parameter on the external habit; $\gamma$, the steady-state growth rate; and $\sigma^{c}$, the inverse of the intertemporal elasticity of substitution. $\ell_{t}, r_{t}$, and $\pi_{t}$ denote the labor supply, the nominal interest rate, and the inflation rate, respectively.

The investment Euler equation is

$$
i_{t}=i_{1} i_{t-1}+\left(1-i_{1}\right) E_{t} i_{t+1}+i_{2} q_{t}+\varepsilon_{t}^{i},
$$

where

$$
\begin{aligned}
& i_{1}=1 /\left(1+\beta \gamma^{\sigma^{c}-1}\right), \\
& i_{2}=1 /\left[\gamma^{2} \varphi\left(1+\beta \gamma^{\sigma^{c}-1}\right)\right],
\end{aligned}
$$

$\beta$ denotes the discount factor of household; $\varphi$, the steady-state elasticity of the capital adjustment cost function; and $\varepsilon_{t}^{i}$, the investment-specific technology shock.

The capital Euler equation is

$$
q_{t}=q_{1} E_{t} q_{t+1}+\left(1-i_{1}\right) E_{t} r_{t+1}^{k}-\left(r_{t}-E_{t} \pi_{t+1}\right),
$$

where

$$
q_{1}=\beta \gamma^{-\sigma^{c}}(1-\delta) .
$$

$q_{t}$ denotes Tobin's $Q$ and $\delta$ denotes the depreciation rate of capital.

The production function is

$$
y_{t}=\phi_{p}\left[\alpha k_{t}^{s}+(1-\alpha) \ell_{t}+\varepsilon_{t}^{a}\right],
$$

where $k_{t}^{s}$ denotes capital service; $\varepsilon_{t}^{a}$, productivity; $\alpha$, the share of capital in production; and $\phi_{p}$, one plus the share of fixed costs in production.

The capital service, $k_{t}^{s}$, is

$$
k_{t}^{s}=k_{t-1}+u_{t}
$$

where $k_{t-1}$ denotes the capital stock at the end of period $t-1$.

The utilization rate, $u_{t}$, is determined by

$$
u_{t}=[(1-\psi) / \psi] r_{t}^{k},
$$

where $\psi$ denotes a positive function of the elasticity of the capital utilization adjustment cost function and normalized to be between zero and one.

The evolution of capital stock, $k_{t}$, is

$$
k_{t}=k_{1} k_{t-1}+\left(1-k_{1}\right) i_{t}+k_{2} \varepsilon_{t}^{i},
$$

where

$$
\begin{aligned}
& k_{1}=(1-\delta) / \gamma, \\
& k_{2}=\left(1-k_{1}\right)\left[\left(1+\beta \gamma^{-\sigma^{c}}\right) \gamma^{2} \varphi\right]
\end{aligned}
$$

The price markup, $\mu_{t}^{p}$ is

$$
\mu_{t}^{p}=\alpha\left[k_{t}^{s}-\ell_{t}\right]+\varepsilon_{t}^{a}-w_{t},
$$

where $w_{t}$ denotes the wage rate.

The Phillips curve with partial indexation is

$$
\pi_{t}=\pi_{1} \pi_{t-1}+\pi_{2} E_{t} \pi_{t+1}-\left(\pi_{3} / \pi_{4}\right) \mu_{t}^{p}+\varepsilon_{t}^{p},
$$

where

$$
\begin{aligned}
& \pi_{1}=\iota_{p} /\left(1+\beta \gamma^{1-\sigma^{c}} \iota_{p}\right), \\
& \pi_{2}=\beta \gamma^{1-\sigma^{c}} /\left(1+\beta \gamma^{1-\sigma^{c}} \iota_{p}\right), \\
& \pi_{3}=\left(1-\beta \gamma^{1-\sigma^{c}} \xi_{p}\right)\left(1-\xi_{p}\right), \\
& \pi_{4}=\left(1+\beta \gamma^{1-\sigma^{c}} a_{p}\right) \xi_{p}\left[\left(\phi_{p}-1\right) \varepsilon_{p}+1\right],
\end{aligned}
$$

$l_{p}$ denotes the degree of indexation to past inflation; $\xi_{p}$, the degree of price stickiness; $\varepsilon_{p}$, the curvature of the Kimball goods market aggregator; and $\varepsilon_{t}^{p}$, the price markup shock.

The rental rate of capital is

$$
r_{t}^{k}=-\left(k_{t}^{s}-\ell_{t}\right)+w_{t}
$$

The wage markup, $\mu_{t}^{w}$, is

$$
\mu_{t}^{w}=w_{t}-m r s_{t},
$$

where

$$
m r s_{t}=\sigma_{\ell} \ell_{t}+\left[c_{t}-(\lambda / \gamma) c_{t-1}\right] /[1-\lambda / \gamma],
$$

and $\varepsilon_{p}$ denotes the elasticity of labor supply with respect to the real wage.

The wage Phillips curve with partial indexation is

$$
\begin{aligned}
w_{t}= & w_{1} w_{t-1}+\left(1-w_{1}\right)\left(E_{t} w_{t+1}+E_{t} \pi_{t+1}\right)-w_{2} \pi_{t}, \\
& +w_{3} \pi_{t-1}+w_{4} /\left(w_{1} w_{5}\right) \mu_{t}^{w}+\varepsilon_{t}^{w}
\end{aligned},
$$

where

$$
\begin{aligned}
& w_{1}=1 /\left(1+\beta \gamma^{1-\sigma_{c}}\right), \\
& w_{2}=\left(1+\beta \gamma^{1-\sigma_{c}} \boldsymbol{c}_{w}\right) /\left(1+\beta \gamma^{1-\sigma_{c}}\right), \\
& w_{3}=\iota_{w} /\left(1+\beta \gamma^{1-\sigma_{c}}\right), \\
& w_{4}=\left(1-\beta \gamma^{1-\sigma_{c}} \xi_{w}\right)\left(1-\xi_{w}\right), \\
& w_{5}=\xi_{w}\left[\left(\phi_{w}-1\right) \varepsilon_{w}+1\right],
\end{aligned}
$$

$\iota_{w}$, denotes the degree of wage indexation; $\xi_{w}$, the degree of the wage stickiness; $\varepsilon_{w}$, the curvature of the Kimball labor market aggregator; and $\varepsilon_{t}^{w}$ denotes the wage markup shock.

The monetary policy is

$$
r_{t}=\rho r_{t-1}+(1-\rho)\left[r_{\pi} \pi_{t}+r_{y} \Delta y_{t}\right]+\varepsilon_{t}^{r},
$$

where $\varepsilon_{t}^{r}$ denotes monetary policy shock. 
The evolutions of shocks are AR(1):

$$
\begin{gathered}
\varepsilon_{t}^{g}=\rho_{g} \varepsilon_{t-1}^{g}+\eta_{t}^{g}, \\
\varepsilon_{t}^{i}=\rho_{i} \varepsilon_{t-1}^{i}+\eta_{t}^{i}, \\
\varepsilon_{t}^{a}=\rho_{a} \varepsilon_{t-1}^{a}+\eta_{t}^{a} \\
\varepsilon_{t}^{p}=\rho_{p} \varepsilon_{t-1}^{p}+\eta_{t}^{p}, \\
\varepsilon_{t}^{w}=\rho_{w} \varepsilon_{t-1}^{w}+\eta_{t}^{w}, \\
\varepsilon_{t}^{r}=\rho_{r} \varepsilon_{t-1}^{r}+\eta_{t}^{r} .
\end{gathered}
$$

Technology shock $\eta_{t}^{a}$ is consist of unanticipated and anticipated components:

$$
\eta_{t}^{a}=v_{0, t}+v_{1, t-1}+v_{2, t-2}+v_{3, t-3}+v_{4, t-4},
$$

where $v_{i, t-i}$ denotes a news shock observed at period $t-i$.

\subsection{Flexible Price-Wage Economy}

We also consider the role of news shocks in the flexible price-wage economy. In this economy, price and wage markups are constant: $\mu_{t}^{p}=\mu_{t}^{w}=0$ and two Phillips curves (10) and (14) are removed from the baseline model.

\section{Main Results}

\subsection{Responses to News Shocks}

Following Christiano, Ilut, Motto, and Rostagno [4], we consider the following impulse. Up until period $t=0$, the economy is at the steady state. At period $t=0$, a news shock hits the economy: $v_{4,0}=0.01$. However, at period $t=4$, the expected rise in productivity does not occur: $v_{0,4}+v_{4,0}=0$. This is interpreted as the news turning out to be false.

We employ parameter values estimated by Fujiwara, Hirose, and Shintani [7] for the Japanese economy.

They estimate parameters using the Bayesian technique $^{2}$. Schmitt-Grohe and Uribe [9] also estimate parameters of a model for NDBCs using the US data. We employ the model of Fujiwara, Hirose, and Shintani [7] since the model of Schmitt-Grohe and Uribe [9] is real and there is no nominal rigidities.

Figure 1 shows the responses of the baseline and the flexible price-wage economies.

Positive comovements of consumption, labor, investment, and output occur $t=0,1,2$ and 3 , but these variables drop $t=4$ since the news turns out to be false. Therefore, NDBCs are generated in the baseline model. However, in the flexible price-wage economy, NDBCs are not generated since consumption moves countercyclically.

\footnotetext{
${ }^{2}$ See Table 1 of Fujiwara, Hirose, and Shintani [7] for estimated values.
}

In order to understand the mechanism, consider our model without capital utilization. By (9), (12) and (13), we obtain

$$
\begin{aligned}
& \left(\sigma_{\ell}+\alpha\right) \ell_{t}+\left[c_{t}-(\lambda / \gamma) c_{t-1}\right] /[1-\lambda / \gamma]+\mu_{t}^{p}+\mu_{t}^{w} \\
& =\alpha k_{t-1}+\varepsilon_{t}^{a}
\end{aligned}
$$

This equation implies that the positive comovements of consumption and labor inputs is possible if the markups, $\mu_{t}^{p}+\mu_{t}^{w}$, decrease sufficiently. High labor implies increase of output, and the news increases investment since the adjustment costs encourage current investment to prepare for the future. In our model, capital utilization is variable, but its response to the news shock is small and NDBCs are generated through the movements of the markups. On the contrary, in the flexible price-wage economy, markups are constant and NDBCs are not generated.

In the model of Christiano, Ilut, Motto, and Rostagno [4], NDBCs are generated even without nominal rigidities. What is the reason of this different result? The important difference between the present model and their one is habit persistence. In our model, habit persistence is external while it is internal in the model of Christiano, Ilut, Motto, and Rostagno [4]. As shown by Nutahara [10], external habit cannot be a source of NDBCs.

\subsection{Price Rigidity versus Wage Rigidity}

NDBCs are not generated in the baseline model if there are no nominal rigidities. Then, which rigidity is important for NDBCs? In order to address this question, we consider the sticky-price economy (wages are flexible) and the sticky-wage economy (prices are flexible). Other settings are the same as in the baseline economy.
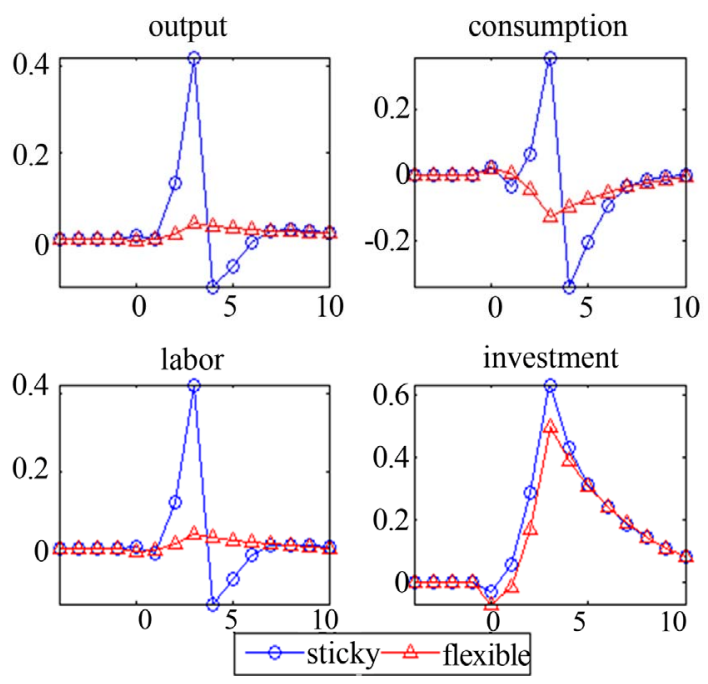

Figure 1. Responses to news shock (1): baseline vs flexible price-wage economy. 
Figure 2 shows the responses of the sticky-price and the sticky-wage economies.

In the sticky-wage economy, consumption moves countercyclically while NDBCs are generated in the stickyprice economy. Kobayashi and Nutahara [6] show that the sticky wages can be a source of NDBCs theoretically since it affects labor wedge: The ratio of the marginal rate of substitution between consumption and leisure to the marginal product of labor. However, our results tell that sticky wages are not sources of NDBCs in an estimated medium-scale DSGE economy.

While sticky wages are not sources of NDBCs, they are important since the responses of the economy with sticky wages to the news shock are large. Then, sticky wages amplify the effect of news shocks.

\section{Conclusions}

In this paper, we focused on nominal rigidities as sources of NDBCs. Our model is a medium-scale DSGE economy a la Smets and Wouters [8] with news shocks on productivity. Using the estimated parameter values of Fujiwara, Hirose, and Shintani [7], we showed that, in this economy, NDBCs are generated since there are nominal rigidities, especially the sticky prices.

Our results imply that nominal price rigidity not only generate persistent responses to unexpected current shocks, but also drive booms and recessions in response to the news shock.
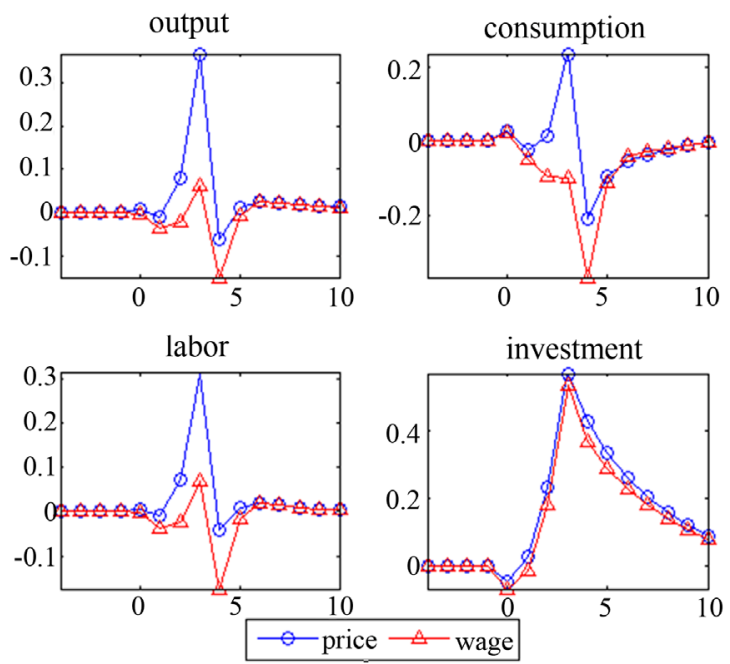

Figure 2. Responses to news shock (2): sticky prices vs sticky wages.

\section{Acknowledgements}

I would like to thank Keiichiro Kobayashi, Masaru Inaba, and an anonymous referee for their helpful comments and suggestions. Of course, the remaining errors are mine.

\section{REFERENCES}

[1] P. Beaudry and F. Portier, "An Exploration into Pigou's Theory of Cycles," Journal of Monetary Economics, Vol. 51, No. 6, 2004, pp. 1183-1216. doi:10.1016/j.jmoneco.2003.10.003

[2] N. Jaimovich and S. Rebelo, "News and Business Cycles in Open Economies," Journal of Money, Credit and Banking, Vol. 40, No. 8, 2008, pp. 1699-1711. doi:10.1111/j.1538-4616.2008.00179.x

[3] N. Jaimovich and S. Rebelo, "Can News about the Future Drive the Business Cycle?" American Economic Review Vol. 99, No. 4, 2009, pp. 1097-1118. doi:10.1257/aer.99.4.1097

[4] L. J. Christiano, C. Ilut, R. Motto and M. Rostagno, "Monetary Policy and Stock Market Boom-Bust Cycles," European Central Bank Working Paper Series 955, 2007.

[5] K. Kobayashi, T. Nakajima and M. Inaba, "Collateral Constraint and News-Driven Cycles," Forthcoming in Macroeconomic Dynamics, Vol. 16, No. 5, 2012, pp. 752776. doi:10.1017/S1365100510000829

[6] K. Kobayashi and K. Nutahara, "Nominal Rigidities, NewsDriven Business Cycles, and Monetary Policy," The B. E. Journal of Macroeconomics, Vol. 10, No. 1, 2010, pp. 1-24. doi:10.2202/1935-1690.2094

[7] I. Fujiwara, Y. Hirose and M. Shintani, "Can News Be a Major Source of Aggregate Fluctuations? A Bayesian DSGE Approach," Journal of Money, Credit and Banking Vol. 43, No. 1, 2011, pp. 1-29. doi:10.1111/j.1538-4616.2010.00363.x

[8] F. Smets and R. Wouters, "Shocks and Frictions in US Business Cycles: A Bayesian DSGE Approach," American Economic Review, Vol. 97, No. 3, 2007, pp. 586-606. doi:10.1257/aer.97.3.586

[9] S. Schmitt-Grohe and M. Uribe, "What's News in Business Cycles?" Econometrica, Vol. 80, No. 6, 2012, pp. 2733-2764. doi:10.3982/ECTA8050

[10] K. Nutahara, "Internal and External Habits and NewsDriven Business Cycles," Economics Letters Vol. 107, No. 2, 2010, pp. 300-303. doi:10.1016/j.econlet.2010.02.018 